\title{
CONHECIMENTO ESPECIALIZADO DE FUTUROS PROFESSORES DA EDUCAÇÃO INFANTIL E ANOS INICIAIS NO ÂMBITO DO PARALELISMO ENTRE RETAS
}

\section{PROSPECTIVE KINDERGARTEN AND PRIMARY TEACHERS SPECIALIZED KNOWLEDGE IN THE SCOPE OF PARALLELISM BETWEEN LINES}

\author{
Silvania Couto ${ }^{1}$, Miguel Ribeiro²
}

\section{RESUMO}

Este artigo integra uma pesquisa que busca entender o conhecimento revelado por Futuros Professores da Educação Infantil e Anos Iniciais sobre conceitos de paralelismo. As informações foram coletadas durante a dinamização de uma tarefa de caráter formativo em uma turma do $3^{\circ}$ Ano do curso de Pedagogia de uma universidade pública paulista, que contou com a participação de 28 licenciandos. A tarefa foi desenhada com o intuito de aceder e desenvolver o Conhecimento Especializado dos futuros professores no âmbito do paralelismo entre retas. As informações foram coletadas tendo como recurso as produções escritas e gravações em áudio e vídeo das discussões em pequeno grupo. A especialização do conhecimento do professor é encarada na perspectiva do Mathematics Teachers' Specialized Knowledge (MTSK) considerado, portanto, parte do conhecimento especializado do professor tanto a dimensão do conhecimento matemático quanto pedagógico. Como resultados destacam-se evidências de conhecimentos relativos à definição de paralelismo entre retas (sustentada na distância), bem como relativos à existência de diferentes formas do registro de representação de retas paralelas como seja a linguagem matemática e a linguagem natural. Revelam ainda indícios de conhecimento relativos a conexões entre paralelismo e outros temas da matemática como a tangente de um ângulo.

PALAVRAS-CHAVE: Conhecimento Especializado. Paralelismo. Futuros Professores da Educação Infantil e Anos Iniciais.

\section{ABSTRACT}

This paper discusses prospective kindergarten and primary teachers' knowledge (PTs) in the scope of parallelism between lines. Data has been collected during the discussion of a task designed for teacher education implemented in the 3rd year of a Pedagogy course of a public University of São Paulo, to 28 prospective teachers. The task was designed with the aim of accessing and developing PTs Specialized Knowledge in the scope of parallelism between lines. Data has been gathered from written productions and audio and video recordings of small group discussions. The specialization of teacher's knowledge is considered in the perspective of the Mathematics Teachers' Specialized Knowledge (MTSK). Results reveal PTs knowledge related to the definition of parallelism between lines (grounded in the distance), as well as related to the existence of different forms of the parallel representation of straight lines such as mathematical language and natural language. Results reveal also evidence of knowledge concerning connections between parallelism and other mathematical topics as the tangent of an angle.

KEYWORDS: Specialized Knowledge. Parallelism. Prospective Kindergarten and Primary teachers.

\footnotetext{
${ }^{1}$ Licenciada em Matemática pela Universidade Federal de Sergipe (UFS). Mestranda em Educação pela Universidade Estadual de Campinas (Unicamp). E-mail: silvaniacoutoc@gmail.com

2 Doutor em Didática da Matemática pela Universidad de Huelva. Professor da Faculdade de Educação da Universidade Estadual de Campinas (Unicamp). E-mail: cmribas78@gmail.com
} 


\section{INTRODUÇÃO}

Um dos tópicos da Geometria apresentado ao aluno a partir do $4^{\circ}$ Ano dos Anos Iniciais, é o paralelismo. Segundo orientação da Base Nacional Comum Curricular - BNCC (BRASIL, 2018), documento norteador da educação brasileira, é inicialmente relacionado com o senso de localização e movimentação e paulatinamente, ao avançar dos anos de ensino, assume maior grau de aprofundamento enveredando pela Geometria Euclidiana, pela Geometria Espacial e pela Geometria Analítica. Uma provável razão para esse enlace entre o paralelismo e a especialidade é ser esse conceito "um dos mais importantes, pois será utilizado ao longo da vida" (ROSSI; OLIVEIRA, 2006, p. 92).

Essa abordagem intuitiva coaduna com estudos de Piaget que provocam, ao final do século XIX, uma mudança radical no entendimento quanto ao que deveria e como deveria ser ensinada a Geometria nos Anos Iniciais, influenciando de modo significativo o ensino da Geometria Euclidiana nesse nível de ensino, tornando-a mais intuitiva e elementar (VALENTE, 2013), e consequentemente interferiu de modo direto no que Markic (2017, p. 42) chama de "processo contínuo e fundamental" que gera "expectativa do professor", a aprendizagem do aluno. Também gerou

[...] o ciclo vicioso, centrado no esquecimento da geometria que tem início no ensino que relega o assunto ao plano mínimo de informação ao educando. Esse procedimento gera o ensino defasado. Ao final, tem como resultado professores despreparados que manterão a mesma qualidade de ensino, fechando o ciclo (ROSSI; OLIVEIRA, 2006, p. 91).

Porém, perpassando as mudanças impetradas pelas pesquisas de Piaget, permanece a notoriedade da influência do conhecimento do professor para aprendizagem do aluno, reforçada por pesquisas que discutem as idiossincrasias desse conhecimento, de modo recorrente e ganhando maior nível de aprofundamento a partir da década de 80 do século passado com Shulman (1986), sendo posteriormente direcionada especificamente para a matemática por Ball, Thames e Phelps (2008), dentre outros. Entretanto, o foco na Especifici- dade do Conhecimento do Professor a partir de temas matemáticos ganharam maior atenção depois do Mathematics Teachers' Specialized Knowledge - MTSK (CARRILLO-YAÑEZ et al., 2018).

O MTSK é um modelo teórico que entende o Conhecimento Especializado do Professor, como uma indissociável combinação entre o seu conhecimento matemático e o seu conhecimento pedagógico, que associados ainda as suas crenças e concepções, são o elemento propulsor para a aprendizagem do aluno (CARRILLO-YAÑEZ et al., 2018). Aqui, pelo enfoque pretendido ser o conhecimento revelado pelos futuros professores aos conceitos do tema paralelismo, a análise embasa-se no seu conhecimento quanto a categorias relacionadas a apenas dois dos subdomínios do MTSK, que tratam respectivamente quanto ao conhecimento dos futuros professores sobre o tema e sobre as conexões deste com outros temas matemáticos.

Entendemos que a compreensão desse elemento propulsor que é o conhecimento do professor torna-se a cada dia mais essencial, na medida em que novas demandas surgem impostas pela organização social em transição (RIBAS et al, 2006), que demanda do professor municiado desse conhecimento, "propiciar melhores condições de aprendizado aos alunos, trazendo em suas relações estímulos para a recuperação de dificuldade" (MARKIC, 2017, p. 44).

Apesar dessas novas demandas, a habilidade da visualização entendida como "[...] atividade, seja mental, seja física, baseada no uso de elementos visuais ou espaciais para resolver problemas ou provar propriedades" (GUTIERREZ, 1996, p. 9, tradução nossa), ajuda o professor a propiciar melhores condições de aprendizagem nas diversas áreas da matemática, inclusive em temas da Geometria como o paralelismo entre retas. O principal argumento a favor disso é o fato da visualização se pautar "num conjunto de imagens, e mais globalmente, nas conceitualizações que um indivíduo pode ter sobre um objeto, sobre uma situação e sobre o que the é associado"(DUVAL, 2012, p. 269). Logo, contribui significativamente para o estudo das posições relativas das retas, que são elementos geométricos que se estendem de infinito a infinito, demandando o uso da visualização para construir a conceitualização sobre paralelismo compreendendo que as retas são equidistantes não apenas no segmento 
retrato no desenho mas em toda sua extensão que abrange o que os olhos não capturam - o infinito.

Por conseguinte, pretende-se aqui discutir o conhecimento de futuros professores da Educação Infantil e Anos Inicias ao responderem uma tarefa em que necessitam mobilizar seu conhecimento ao atribuir significado a produções escritas de alunos sobre problemas quanto ao paralelismo. $O$ ponto de partida das discussões é a análise das resoluções de uma tarefa desenhada para a formação de professores (RIBEIRO, 2016), implementada em uma turma do $3^{\circ}$ ano de Pedagogia de uma Universidade Pública do Estado de São Paulo, com o apoio das vídeo gravações das discussões em grupo das quais decorreram. Desse modo busca-se à resposta a seguinte questão de pesquisa: Que Conhecimento Especializado revelam Futuros Professores da Educação Infantil e Anos Iniciais, considerando definições e inter-relações com temas matemáticos, ao responderem tarefas desenhadas para atribuírem significado às respostas de alunos sobre paralelismo?

\section{FUNDAMENTAÇÃO TEÓRICA}

Entendemos o conhecimento do professor como sendo especializado e nesse sentido consideramos - Mathematics Teachers' Specialized Knowledge MTSK (CARRILLO-YAÑEZ et al., 2018). Esse modelo teórico (Figura 1), conceitualiza o conhecimento do professor como um recurso usado em seu cotidiano profissional composto por seus conhecimentos sobre conteúdos matemáticos (Mathematical Knowledge - MK) e aspectos do ensino fundamental da aprendizagem do aluno (Pedagogical Content Knowledge - PCK), levando em conta ainda suas crenças e concepções. Essa mistura indissociável entre o conhecimento matemático e pedagógico do professor que ensina matemática, reveste-se de idiossincrasias únicas à sua prática, que o diferenciam de outras áreas do conhecimento que fazem uso da Matemática no sentido instrumental, por sua função precípua se usar seu conhecimento em prol da aprendizagem Matemática do aluno.

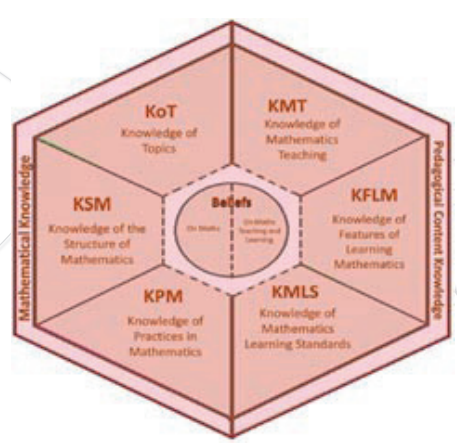

Figura 1 - Mathematics Teachers' Specialized Knowledge Fonte: Carrillo-Yañez et al (2018, p. 241)

Os seis subdomínios que constituem o MTSK alocam-se três a três em cada um dos domínicos (MK e PCK) de forma não hierarquizada. Desse modo, faz parte do domínio do MK: o Knowledge of Topics (KoT), o Knowledge of the Structure of Mathematics (KSM) e o Knowledge of the Practice of Mathematics (KPM). Por sua vez, compõe o domínio do PCK, o Knowledge of Features of Learning Mathematics (KFLM), o Knowledge of Mathematics Teaching (KMT) e o Knowledge of Mathematics Learning Standards (KMLS). Perpassando a ambos domínios se tem as crenças e concepções do Professor sobre a Matemática enquanto área do conhecimento e sobre o seu ensino.

Além disso, cada subdomínio se consubstancia a partir de categorias a serem observadas com base em indicadores oriundos das produções orais e/ou escritas dos professores. Esses indicadores podem vir em forma de evidências, indícios ou oportunidades (ESCUDERO-ÁVILA et al, 2016). Entende-se como evidências, a observação direta do conhecimento associado ao subdomínio em sua fala ou produção escrita. Os indícios são suposições com base em pistas (palavras, questionamentos ou atos do professor) que dão a entender a existência do conhecimento sobre o tema, demandando interversão direta (a exemplo de entrevista) para se consolidar numa evidência. Já as oportunidades, são os momentos em que mesmo fugindo ao planejado para aula, o professor revela o seu conhecimento sobre um tema matemático correlato.

Ressalta-se que devido ao enfoque pretendido, pautado no tema matemático paralelismo considerando a sua definição e a sua conexão com outros temas da matemática, a análise das informações coletadas restringe-se nesse artigo aos subdomínios KoT e KSM. 
Tal opção, fulcra-se na compreensão de que por tratarse de uma pesquisa em Educação Matemática é imperativo discutir o conhecimento matemático envolvido.

Desse modo, o Knowledge of Topics (KoT) refere-se ao conhecimento do professor sobre o tema matemático em apreço abrangendo um maior nível de aprofundamento do que será discutido com o aluno. Este subdomínio tem como categorias que aqui serão analisadas, dentre outras: definições, propriedades e seus fundamentos, procedimentos e sistemas de representações.

Considera-se o conhecimento do professor no âmbito da categoria definições quanto ao paralelismo saber que no campo da Geometria Euclidiana é o estudo das suas posições relativas. Também saber que o paralelismo se configura entre duas ou mais retas quando existe um mesmo plano que as contenha mantendo a equidistância. Quando os elementos geométricos forem um plano e uma reta, essa não pode pertencer ao plano, mas deve ser paralela a uma reta nele contida.

Logo, como a equidistância entre as retas que tem um plano em comum implica no seu não cruzamento, constitui-se ainda como conhecimento especializado do professor, no âmbito da mesma categoria, saber que duas retas são paralelas quando não se cruzam tendo um plano em comum. Portanto, como retas coincidentes não se cruzam e têm todos seus pontos em comum e consequentemente estão no mesmo plano, também configura esse conhecimento, saber que por questões de coerência matemática, retas coincidentes também são consideradas paralelas.

Ainda se configura conhecimento especializado do professor no computo dessa categoria, saber que no âmbito da Geometria Analítica, duas retas são paralelas quando possuem o mesmo coeficiente angular e que a igualdade de coeficiente equivale a dizer que as retas possuem a mesma inclinação, sendo, portanto, também uma definição para retas paralelas.

Por conseguinte, aproveitando-se das conceitualizações sobre coesão e coerência oriundas da linguística (GONÇALVES; DIAS, 2003) entende-se como constituinte do conhecimento do professor no âmbito da categoria fundamentos saber que, no que tange ao paralelismo entre retas, afirmar que retas paralelas são as que possuem a mesma inclinação e o mesmo coeficien- te angular apresenta problemas de coesão matemática, pois estas informações são equivalentes consequentemente, figurarem, vinculadas pelo conectivo "e" como ideias complementares reflete redundância.

De igual modo, também constitui o conhecimento do professor na categoria propriedades, saber que a afirmação de que são paralelas por não terem nenhum ponto em comum apresenta problemas de coerência matemática, pois exclui as retas coincidentes de serem paralelas. Além disso, ainda compõe o conhecimento do professor na mesma categoria, saber que afirmar somente que são paralelas retas que não se cruzam, apresenta problemas de completude matemática, pois faz-se necessário que tenham um plano em comum, do contrário, retas reversas também seriam paralelas, pois não se cruzam.

No que tange a categoria procedimentos, subcategoria como se faz, configura o conhecimento especializado do professor saber que a habilidade da visualização é um forte aliado na construção da conceitualização de paralelismo (DUVAL, 2012), pois a questão da equidistância abrange toda a extensão da reta que vai de infinito a infinito e não apenas o expresso no desenho, demandando o desenvolvimento da construção de imagens mentais intrínsecas à visualização. Ainda envolve saber que essa habilidade pode inclusive ser um aliado na sedimentação de relações intraconceituais como a não concorrência entre retas, que sedimenta o paralelismo. Também está no escopo dessa categoria saber que em todas essas situações de aprendizagem se pode fazer uso de atividades físicas como medir, com o intuito de confirmar suas hipóteses e isso também faz parte da visualização (GUTIERREZ, 1996).

Com respeito a categoria registro de representações, constitui-se conhecimento especializado do professor sobre paralelismo saber que ele pode ser representado não somente em linguagem natural como expresso nas definições dos parágrafos precedentes, em linguagem matemática em que se utiliza de linguagem científica caracterizada pelo uso de símbolos próprios para os quais são atribuídos valores semânticos (DUVAL, 1999), como, sendo $\boldsymbol{s}$ e $\boldsymbol{t}$ retas encaradas como conjuntos de infinitos e sucessivos pontos perfilados teremos: , ou ainda podemos representar retas paralelas como s//t. 
Por sua vez, o Knowledge of the Structure of Mathematics (KSM) versa sobre o conhecimento do professor com respeito as conexões interconceituais que relaciona o que se está estudando a outros temas matemáticos de menor grau de complexidade (conexões baseadas na simplificação) ou mais complexos (conexões baseadas no aumento da complexidade), auxiliares ou transversais. Nesse artigo a análise por conta do problema eleito se pautará nas conexões baseadas no aumento da complexidade.

Assim, no que tange ao tema paralelismo entre retas, os conhecimentos incluídos nesse subdomínio permitem que o professor se utilize de assuntos de maior complexidade como o são a compreensão do papel da tangente de um angulo frente o tema do paralelismo apresentado de forma introdutória aos alunos dos Anos Iniciais (VALENTE, 2013).

Desse modo, conhecer os cálculos para a obtenção da tangente do ângulo que a reta forma com o eixo das abcissas é uma evidência do seu KSM na categoria conexões baseadas no aumento da complexidade, já que permite ao professor lançar base para a abordagem de outras posições relativas das retas, como o perpendicularismo. Também está no escopo dessa categoria, saber que a tangente de um ângulo de $90^{\circ}$ não existe, uma vez que o estudo das relações trigonométricas se dá com base no triângulo retângulo, sendo necessário, portanto, um ângulo de $90^{\circ}$ e três lados denominados catetos adjacente, cateto oposto e hipotenusa, respectivamente.

Logo, também ainda está no escopo desse conhecimento saber que no círculo trigonométrico o triângulo retângulo se configura pelo encontro dos lados que determinam a amplitude do ângulo com a reta que o tangencia. Entretanto, quando essa amplitude é um ângulo de $90^{\circ}$, não há intersecção entre a reta tangente e a reta que determina a amplitude do ângulo, o que torna a tangente desse ângulo inexistente. Constitui também este conhecimento saber que o cruzamento de uma reta com um feixe de retas paralelas determina, em cada ponto de cruzamento, dois pares iguais de ângulos opostos pelo vértice, pois esse conhecimento se relaciona com outros conteúdos da trigonometria como ângulos complementares e suplementares e como a igualdade de ângulos opostos pelo vértice.

\section{CONTEXTO E MÉTODO}

A presente pesquisa de caráter qualitativo busca compreender o contexto investigado com maior aprofundamento, por meio de um estudo de caso instrumental (STAKE, 1995). Desse modo tem-se aqui um recorte das análises de informações colhidas na implementação e dinamização de uma tarefa que integra uma pesquisa de mestrado cujo objetivo é melhor entender o Conhecimento Especializado de futuros professores da Educação Infantil e Anos Iniciais ao resolverem uma tarefa formativa sob o tema paralelismo.

Por conseguinte, foi implementada uma sequência de tarefas junto a uma turma do $3^{\circ}$ Ano de futuros professores da Educação Infantil e Anos Iniciais de uma universidade pública do Estado de São Paulo, com duração de quatro horas cada. E nesse artigo, discutimos o recorte feito em uma delas em que participaram 28 futuros professores dispostos em 7 grupos com 4 integrantes em cada.

Devido ao seu caráter formativo (RIBEIRO, 2016), as tarefas foram desenhadas com vistas a aceder e desenvolver ao Conhecimento Especializado desses futuros professores da Educação Infantil e dos Anos Iniciais sobre o tema paralelismo, pautando-se na visualização. Compunham-se por três partes complementares, na primeira faz-se a prospecção do conhecimento deles quanto ao tema, na segunda são levados a uma simulação de um contexto inclusivo (alunos cegos e não cegos) e na terceira são convidados a atribuir significado a soluções de alunos, revelando o seu conhecimento mobilizado para esse fim.

Elegemos o problema sobre o qual discorre esse artigo (Figura 2), por viabilizar discussões sobre o conhecimento mobilizado pelos futuros professores quanto a questões do paralelismo entre retas, como as propriedades que o fundamentam, bem como sobre conexões com conceitos da Geometria Analítica e conteúdos de trigonometria que mesmo não sendo empregados nas discussões com os alunos compõe o aporte teórico do tema.

Desse modo, as soluções das alunas apresentadas no problema proposto tinham o objetivo de fomentar discussões sobre as diferenças e semelhanças entre as conceitualizações embasadas na definição e 
na visualização, bem como quanto a problemas de coesão, coerência e completude matemáticas. Por conseguinte, a resolução proposta por Carla (Figura 2) pauta-se na definição, trazendo elementos da Geometria Analítica como o coeficiente angular, entretanto, também traz problemas de coesão, pois se duas retas têm a mesma inclinação forçosamente terão o mesmo coeficiente angular.

A professora Nadja implementou na sua turma do $4^{\circ}$ ano,em que tem três alunos cegos, uma tarefa relacionada com o paralelismo e perpendicularismo. Abaixo encontram-se algumas produções dos alunos. Para cada uma delas relate, justificando, se estão matematicamente corretas, e forneça um feedback construtivo para cada um dos alunos que considere terem respondido de forma não completamente correta (não se restringindo a "parabéns você acertou" ou "você conseguirá na próxima"):

3. As representações abaixo podem ser relacionadas com paralelismo? E perdendicularismo? Justifique. a)

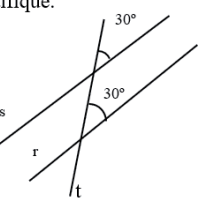

Carla (aluna cega): " $s$ " $e$ " $r$ " são paralelas porque têm a mesm inclinação de $30^{\circ}$ e possuem o mesmo coeficiente angular

Alessandra: As retas " $r$ " $e$ " $s$ " mantêm a mesma distância entre si em todo seu comprimento e não têm nenhum ponto em comum, por isso são paralelas.
Figura 2 - Enunciado da tarefa

Fonte: Produção dos autores.

Já a resolução de Alessandra (Figura 2), pautase na visualização ao referir-se a "todo seu comprimento" tendo por base elementos da Geometria Euclidiana (KoT: definição), entretanto, apresenta problemas de coerência matemática, pois ao afirmar que uma das razões para serem paralelas é que as retas "não têm nenhum ponto em comum" exclui a hipótese de retas coincidentes serem paralelas.

Quanto ao processo empregado na dinamização da tarefa, consistiu na entrega de cada parte da tarefa por vez, passando-se a seguinte apenas quando todos os grupos concluíam a anterior finalizando as discussões com a proposição de uma solução escrita. Esse procedimento, teve o intuito de evitar que as partes seguintes influenciassem as soluções apresentadas aos problemas das partes que a antecediam, devido ao seu caráter complementar. Ressaltamos que toda a produção escrita foi recolhida ao final do processo e escaneada para proceder a análise e que cada um dos seis grupos teve as discussões que sustentaram as soluções escritas, gravadas por meio de equipamento de vídeo direcionado exclusivamente a ele.

Para efetuar a transcrição das discussões fomentadoras, foram ouvidas as gravações de cada grupo por item da tarefa e foram atribuídos nomes fictícios a cada participante. Os gestos ou manipulação de algum objeto presentes na gravação, necessários a compreensão da fala, foram descritos entre parênteses logo após a respectiva fala e nas situações em que as discussões dos subgrupos não se relacionavam com o tópico em foco optou-se por colocar reticências. Todas as discussões foram transcritas integralmente, seguindo Ribeiro, Carrillo e Monteiro (2012), sendo, cada episódio de discussão numerado as linhas de forma sequencial entre colchetes. Complementado essa parte do trabalho, as transcrições foram lançadas em um quadro ao lado da legenda da produção escrita de cada grupo.

Como procedimento de análise procurou-se identificar nas produções escritas o conhecimento revelado pelos futuros professores, agrupando-as segundo a relação possível entre essas e as dimensões do MTSK focando nos subdomínios Knowledge of Topics (KoT) e Knowledge of the Structure of Mathematics (KSM) e usando as transcrições das gravações das discussões fomentadoras para melhor entender o como chegaram as resoluções apresentadas (CARRILLO-YAÑEZ et al., 2018; CARRILLO, 1998). As discussões foram feitas a partir do conjunto de evidências, indícios ou oportunidades observadas que fundamentam o conjunto do conhecimento revelado.

Apresenta-se esse conjunto de forma sintética, ao final da sessão "análises e discussões", em um quadro onde cada conhecimento identificado foi associado a um acrônimo do subdomínio a ele correspondente seguindo de letras que identificam a categoria associada e um número sequencial para distinguir conhecimentos de uma mesma categoria. Desse modo, KoTD1 refere-se ao conhecimento um do subdomínio KoT na categoria definições e assim segue para as demais categorias do KoT e do KSM identificadas.

\section{ANÁLISE E DISCUSSÕES}

Os futuros professores revelaram seu conhecimento sobre o paralelismo entre retas em diferentes níveis, através de suas produções orais (capturadas em vídeo) e escritas. Esse conhecimento Ihes permitiu atribuir significado as soluções apresentadas pelas alunas da professora Nadja (Figura 2) e foi acedido tanto nas discussões dos pequenos grupos quanto na discussão plenária. 
Ao afirmarem que as resoluções de ambas as alunas apresentadas no problema proposto estavam certas, evidenciaram seu conhecimento especializado sobre o tema paralelismo, pois ambas as respostas estão parcialmente corretas, entretanto têm problemas de coerência, coesão e completude matemáticas que não foram levantados.

Os futuros professores aceitaram como certas as soluções apresentadas (Figura 3), revelando saber que as respostas de Carla e Alessandra (Figura 2) são perspectivas distintas para uma conceitualização de paralelismo entre retas. Desse modo, revelaram indícios de saber que Carla pautou-se na definição fundamentando suas afirmações em elementos da Geometria Analítica - inclinação e coeficiente angular (KoTD2), enquanto Alessandra fez uso da visualização, evocando a Geometria Euclidiana - equidistância em toda a extensão das retas (KoTD1).

3) at As divas explicazias estäo coretas, com a diferencas de que a Carba utilizo de uma linguagem matemática e a Alessandra

3) a) As duas explicações estão corretas, com a diferença de que a Carla utiliza de uma linguagem matemática e a Alessandra de maneira mais usual, coloquial.

Figura 3 - Produção apresentada.

Fonte: Acervo dos pesquisadores.

Entretanto, faltou uma discussão sobre as questões de coesão, coerência e completude matemáticas. Essa discussão evidenciaria saber que a resposta de Carla: "são paralelas por terem a mesma inclinação de $30^{\circ}$ e possuem o mesmo coeficiente angular", apresenta problemas quanto a coesão matemática, uma vez que as duas sentenças são equivalentes e não complementares (KoTF3). E saber que Alessandra assevera serem retas paralelas por "... não terem nenhum ponto em comum" é matematicamente incoerente, pois retas coincidentes têm todos os pontos em comum e são paralelas (KoTP1). Também saber que a resposta de Alessandra de configurar paralelismo por "mantêm a mesma distância entre si em todo o seu cumprimento" está incompleta (KoTP2), pois retas reversas não se cruzam, porém não são paralelas por não possuírem um plano comum

Além disso, ao assegurarem que "a Carla utiliza de uma linguagem matemática e a Alessandra de maneira mais usual, coloquial. ", dão indícios de saberem que existem diferentes sistemas de representações (KoTRR1), embora necessite uma melhor discussão quanto ao que é uma linguagem matemática, pois a linguagem matemática é fulcrada na linguagem cientifica que por sua vez, se pauta em símbolos. Entretanto Carla não se utilizou de simbologia matemática e sim de termos que compõe o jargão da matemática, consequentemente, não foi empregada uma linguagem matemática e sim palavras do repertório da matemática.

Também chama a atenção a discussão fomentadora de um dos grupos, na Figura 4 linha [1], que dá indícios do seu conhecimento especializado sobre paralelismo sob a perspectiva da Geometria Analítica ao revelar saber que existe uma relação de equivalência entre a igualdade dos coeficientes angulares das retas e terem a mesma inclinação (KoTF1):

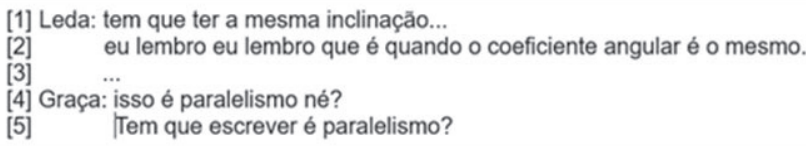

Figura 4 - Transcrição sobre igualdade do coeficiente angular Fonte: Acervo da pesquisa

Notamos que a partir da fala de Leda, outra estudante (Graça), manifestou também conhecer que duas retas terem o mesmo coeficiente angular já implica em serem paralelas (KoTD2), ao perguntar "isso é paralelismo, né?" [4], ratificando o conhecimento desses futuros professores sobre paralelismo, embora tenha sido desperdiçada uma oportunidade de revelar seu conhecimento aos problemas de coesão presentes na resposta de Carla.

Similarmente, notamos oportunidades de discussão de conexões intraconceituais, ao trazer à baila nas discussões fomentadoras o questionamento do que significaria esse ângulo de $30^{\circ}$ [1], conforme excerto que segue na Figura 5.

[1] Marcos: Mas o que a gente pode deduzir desse ângulo de $30^{\circ}$ ?

[2] Esse ângulo é outra forma de você resolver se elas são paralelas

[3] Porque eu demonstro para os meus alunos.

[4] Então acho que deveria demonstrar porque o ângulo de $30^{\circ}$ [5] Luis: Porque é sempre igual.

[6] Marcos: Vai demonstrar para um aluno do quarto ano?

Figura5 - Transcrição sobre o ângulo de $30^{\circ}$

Fonte: Acervo da pesquisa 
Notamos uma oportunidade de revelar conhecer a relação intraconceitual entre a igualdade de amplitude e paralelismo entre retas (KoTF2), uma vez que o contexto envolvido na resolução da tarefa não demandava a demonstração, porém embora tenham achado que seria interessante fazê-lo, desistiram, argumentando que esse conteúdo programático compõe um nível de escolaridade posterior ao do aluno em questão [6].

A constatação de que as respostas estavam parcialmente corretas veio seguida de evidências do seu conhecimento especializado no âmbito das conexões interconceituais. Embora essas não aparecem em sua produção escrita (Figura 6), pois nela apenas fazem alusão a ausência da resposta quanto ao perpendicularismo e a necessidade de Alessandra fazer menção à igualdade da inclinação das retas, podemos extrair evidências do seu conhecimento especializado nos subdomínios KSM e KoT das discussões fomentadoras.

3) at As duas explicacias estäo coretas, com a diferenter de que a Corba sitilizo de umra linguagem matemática e a Alessandra te maniera mais urral, coloquial

3) Carla - está correto. Só faltou o responder sobre o perpendicularismo que neste caso não ocorre, visto que onde há o encontro das retas não há formação de ângulos de $90^{\circ}$ graus Alessandra - exatamente Alessandra, elas não se cruzam, além disso, como disse Carla, as linhas s e $r$ tem a mesma inclinação de 30 graus

Figura 6 - Produção apresentada.

Fonte: Acervo da pesquisa

Por conseguinte, no excerto da discussão que segue (Figura 7), os futuros professores revelam saber que a visualização é um aliado na construção da conceitualização do paralelismo, pois Valda afirma em [1] que "Ele tem o mesmo ângulo aqui e o mesmo ângulo aqui (apontando para os ângulos de $30^{\circ}$ presentes no desenho)." (KoTPcf1). Do mesmo modo, evidenciam saber que o cálculo da tangente desse ângulo é necessário para chegar ao coeficiente angular da reta, por Valda assegurar em [2]: "Tem que saber qual a tangente desse ângulo para saber qual é o coeficiente angular," (KSMAC1), reconhecendo, porém, que a resolução do problema em questão não demanda esse cálculo.

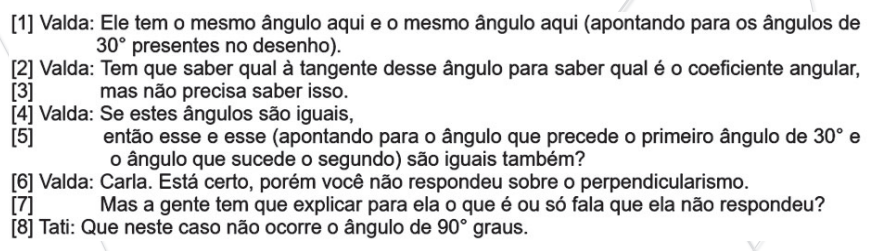

Figura 7 - Discussão sobre ângulos.

Fonte: Acervo da pesquisa

Notamos ainda em [5] com a pergunta "... esse e esse são iguais também?" surge uma oportunidade para fazer uma relação interconceitual com o tema ângulos em que o conhecimento dos futuros professores seria saber que ângulos opostos pelo vértice são iguais (KSMAC2), mas, não fizeram uso dessa oportunidade.

Além disso, tanto na Figura 7, linha [8], quanto na produção escrita em seu feedback para Alessandra (Figura 6) quando afirmam que não são perpendiculares porque "... onde há o encontro das retas não há formação de ângulos de $90^{\circ}$ graus", notamos indícios de que os futuros professores sabem que a amplitude do ângulo que as retas formam entre si influência nas suas posições relativas e que no caso das retas concorrentes formarem um ângulo de $90^{\circ}$ Ihes dá o nome particular de perpendiculares (KSMAC3).

Apresentamos no Quadro 1, uma síntese do conhecimento dos futuros professores (evidências, indícios e oportunidades) considerando os subdomínios em que estes se enquadram e os indicadores associados. 


\begin{tabular}{|c|c|c|}
\hline Subdomínios & Conhecimentos & \\
\hline \multirow{9}{*}{ KoT } & \multirow{2}{*}{ Definições } & $\begin{array}{l}\text { KoTD1: saber que retas paralelas são as que não se cruzam/são equidistantes e têm o } \\
\text { mesmo plano em comum }\end{array}$ \\
\hline & & $\begin{array}{l}\text { KoTD2: saber que retas paralelas são as que têm o mesmo coeficiente angular/ } \\
\text { inclinação }\end{array}$ \\
\hline & & $\begin{array}{l}\text { KoTF1: conhecer que existe equivalência entre as afirmações que as retas possuem a } \\
\text { mesma inclinação e que possuem o mesmo coeficiente angular }\end{array}$ \\
\hline & Fundamentos & $\begin{array}{l}\text { KoTF2: conhecer a relação interconceitual entre a igualdade de amplitude angular e } \\
\text { paralelismo entre retas }\end{array}$ \\
\hline & & KoTF3: saber que a afirmações equivalentes não são complementares \\
\hline & Propriedades & $\begin{array}{l}\text { KoTP1: saber que a afirmação de que retas paralelas não têm ponto em comum é } \\
\text { incoerente }\end{array}$ \\
\hline & & KoTP2: saber que apenas não se cruzarem não define o paralelismo entre retas \\
\hline & $\begin{array}{l}\text { Procedimentos } \\
\text { - como se faz? }\end{array}$ & $\begin{array}{l}\text { KoTPcf1: saber que a visualização é uma auxiliar na construção da conceitualização de } \\
\text { paralelismo entre retas }\end{array}$ \\
\hline & $\begin{array}{l}\text { Registros de } \\
\text { Representação }\end{array}$ & KoTRR1: conhecer a existência de diferentes formas de registro de representação \\
\hline \multirow{3}{*}{ KSM } & \multirow{3}{*}{$\begin{array}{l}\text { Conexões } \\
\text { baseadas no } \\
\text { aumento de } \\
\text { complexificação }\end{array}$} & $\begin{array}{l}\text { KSMAC1: saber que é possível calcular a tangente de um ângulo para chegar ao } \\
\text { coeficiente angular }\end{array}$ \\
\hline & & KSMAC2: saber que ângulos opostos pelos vértices são iguais \\
\hline & & KSMAC3: conhecer a influência da amplitude do ângulo na posição relativa das retas \\
\hline
\end{tabular}

Quadro 1. Resumo do Conhecimento dos futuros professores 


\section{CONSIDERAÇÕES FINAIS}

Os resultados aqui explanados, em termos dos indicadores de conhecimento obtidos a partir da análise e discussão (por futuros professores da Educação Infantil e Anos Iniciais) de um conjunto de produções de alunos, permitem simultaneamente ampliar e aprofundar o entendimento que se detém relativo ao conhecimento especializado do futuro professor e ao conteúdo das suas dimensões - particularmente no que se refere as definições e conexões entre tópicos envolvendo paralelismo.

Esse entendimento ampliado, perspectiva a possibilidade e necessidade de uma mudança de foco na formação de professores, considerando a importância de que essa formação tenha como finalidade possibilitar que os professores venham a ter um efetivo desenvolvimento posterior de práticas matemáticas que possibilitem aos seus alunos entenderem o que fazem e por que o fazem, a cada momento. Para que esse tipo de prática possa se tornar efetiva de forma global, é essencial que durante a sua formação inicial (e continuada) sejam confrontados com situações da prática - que a pesquisa mostra que são matematicamente críticas (RIBEIRO; CARRILLO, 2011) - que sejam exploradas com a intencionalidade de desenvolver as especificidades do seu conhecimento especializado já que as dimensões matemáticas deste é algo que não se desenvolve na prática (JAKOBSEN; RIBEIRO; MELLONE, 2014).
Assim, os indicadores de conhecimento aqui identificados, são considerados bons pontos de partida para a elaboração de tarefas para a formação de professores (tarefas formativas) sempre e quando se objetive que essa formação promova o desenvolvimento do conteúdo de diferentes subdomínios do conhecimento do professor de/que ensina matemática (RIBEIRO; ALMEIDA; MELLONE, 2019). A elaboração destas tarefas formativas, ainda que não tenha sido foco de discussão aqui, é um dos elementos centrais para perspectivar a melhoria da qualidade da formação de professores e ampliar o entendimento que possuímos do conteúdo do seu conhecimento e de formas de o desenvolver - considerando pesquisa e formação de professores de forma imbricada.

Nesse sentido, algumas questões que ficam ainda em aberto e que podem guiar trabalhos futuros que busquem contribuir para a discussão sobre o conhecimento do professor e as especificidades desse conhecimento para a melhoria da prática referem-se a, por exemplo: (i) o conteúdo e papel do conhecimento de (futuros) professores no âmbito da visualização nas abordagens aos paralelismo (e não somente de retas); (ii) ao conhecimento especializado revelado por (futuros) professores relativamente as dificuldades dos alunos no tópico de posição relativa de "objetos e entes matemáticos" e propostas para enfrentar essas dificuldades.

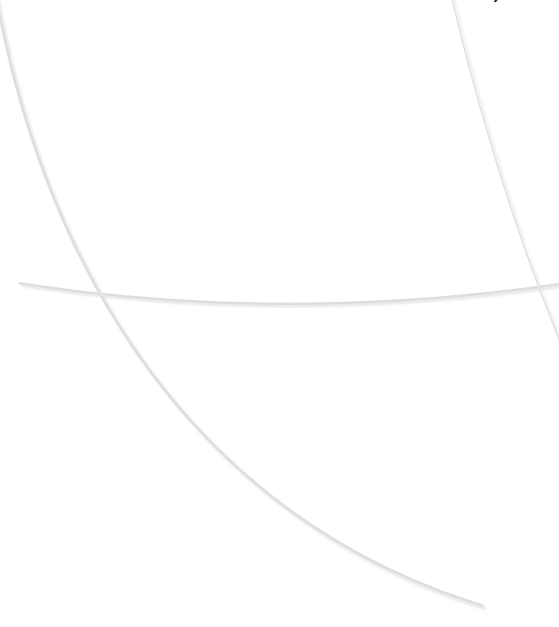




\section{Agradecimentos:}

Este texto foi produzido no âmbito do projeto "Conhecimento matemático especializado do professor que ensina Matemática na Educação Infantil e nos Anos Iniciais: um foco em conteúdos de Geometria", processo número 2016/22557-5, com financiamento da Fundação de Amparo à Pesquisa do Estado de São Paulo (FAPESP).

\section{REFERÊNCIAS}

BALL, D. L.; THAMES, M. H.; PHELPS, G. Content Knowledge for Teaching: What makes it special? Journal of Teacher Education, v. 59, n. 5, p. 389407, 2008.

BRASIL. Base Nacional Comum Curricular. Brasília, DF: Ministério da Educação, 2018.

CARRILLO, J. Modos de resolver problemas y concepciones sobre la matemática y su enseñanza: Metodología de la investigación y relaciones. Edición: 1 ed. Huelva: Universidad de Huelva, 1998.

CARRILLO, J. et al. The mathematics teacher's specialised knowledge (MTSK) model. Research in Mathematics Education, p. 1-18, 2018.

CARRILLO-YAÑEZ, J. et al. The mathematics teacher's specialised knowledge (MTSK) model*. Research in Mathematics Education, v. 20, n. 3, p. 236-253, 2 set. 2018.

DUVAL, R. Registros de representação semiótica e funcionamento cognitivo do pensamento. Revemat: Revista Eletrônica de Educação Matemática, v. 7, n. 2, p. 266-297, 2012.

DUVAL, R. Representation, vision and visualization: cognitive functions in mathematical thinking. In: Basic Issues For Learning, 1999, Cuernavaca, Morelos, Mexico. Anais... Cuernavaca, Morelos, Mexico: [s.n.], p. 23-26, 1999.

ESCUDERO-ÁVILA, D. et al. Aportaciones metodológicas de investigaciones con MTSK. In: Reflexionando Sobre El Conocimiento Del Profesor, 2016, SGSE: Huelva. Anais... SGSE: Huelva: J. Carrillo, L.C. Contreras y M. Montes, p. 60-68, 2016.

GONÇALVES, F.; DIAS, M. DA G. B. B. D. Coerência Textual: Um Estudo com Jovens e Adultos. Psicologia: Reflexão e Crítica, v. 16, n. 1, p. 29-40, 2003.
GUTIERREZ, A. Visualization in 3-dimensional geometry search of a framework.: L. Puig \& A. Gutiérrez (eds), Proceedings of the 20th Conference of the International Group for the Psychology of Mathemamatics Education, v. 1, n. 20, p. 3-19, 1996.

JAKOBSEN, A.; RIBEIRO, M.; MELLONE, M. Norwegian prospective teachers' MKT when interpreting pupils'production on a fraction task. Nordic Studies in Mathematics Education, v. 19, n. (3-4), 2014.

MARKIC, A. A. Tecitura: Afetividade e Aprendizagem Na Educação Infantil. Revista Educação - Universidade de Guarulhos, v. 12, n. 2, p. 42-51, 2017.

RIBAS, T. R. C. et al. As diferentes dimensões da "Competência" Na formação do profissional-professor. Revista Educação - Universidade Guarulhos, v. I, n. 2, p. 43-49, 2006.

RIBEIRO, M. T. Areas para alumnos y tareas para la formación: discutiendo el conocimiento especializado del profesor y del formador de profesores de matemáticas. In: XX JORNADAS NACIONALES DE EDUCACIÓN MATEMÁTICA - SOCHIEM, 2016, Valparaíso: Chile. Anais... Valparaíso: Chile: [s.n.], p. 31-39, 2016.

RIBEIRO, M.; CARRILLO, J. Knowing mathematics as a teacher. In: CERME 7, 2011, Rzeszów. Anais... Rzeszów: ERME, 2011. p. 2818-2826.

ROSSI, V.; OLIVEIRA, C. C. DE. As dimensões da etnomatemática na construção do conceito de espacialidade: um estudo para a primeira série do ciclo I. Revista da Educação da Universidade de GuaruIhos, v. I, n. 1, p. 89-92, 2006.

SHULMAN, L. Those who understand: Knowledge growth in teaching. Educational Researcher, $\mathrm{n}$. 15(2), p. 4-14, 1986.

STAKE, R. E. The art of case study research. 1. ed. Thousand Oaks, CA: Sage Publications, 1995.

VALENTE, W. R. Que geometria ensinar? Uma breve história da redefinição do conhecimento elementar matemático para crianças. Pro-Posições, v. 24, n. 1, p. 159-178, abr. 2013. 